\title{
Reformation and Practice of Higher Vocation Curriculum Based on NB Industry Chain
}

\author{
Zhongbo Deng ${ }^{1}$, Xinyuan Liang, ${ }^{2, *}$, Caixia Guo ${ }^{3}$ and Qiang Yao ${ }^{4}$ \\ ${ }^{1}$ Chongqing Information Technology College, Chongqing, China \\ ${ }^{2}$ Chongqing Technology and Business University, Chongqing, China \\ ${ }^{3}$ Chongqing Municipal Agricultural School, Chongqing, China \\ ${ }^{4}$ Chongqing Academy of Agricultural Sciences, Chongqing, China \\ ${ }^{*}$ Corresponding author
}

\begin{abstract}
According to the requirement changing of personnel market, the personnel training mode and curriculum set in higher vocational colleges must be adjusted to better meet the requirement of personnel market and solve the graduate employment problem of higher vocational college. This paper introduced the situation of personnel requirement and the vocational attainment of NB (notebook) industry chain. This paper put up specialties related to cultivate these professionalisms. These specialties include computer technology, electronic information technology, applied electronic technology, enterprise management, e-commerce, logistic, and so on. Then, this paper took the practice of curriculum reform on related specialties around NB industry chain in Chongqing Information Technology College. Finally, the paper discussed how to reform curriculum of related specialties for the NB industry chain, so that the reformed curriculum system closely served NB industrial chain. It is better meet the actual requirements, and more beneficial to cultivate higher vocational students' post skill. The practice proves that, the curriculum reform around the NB industry chain is effective.
\end{abstract}

Keywords-notebook (nb); industry chain; higher vocation; curriculum system; practice

\section{INTRODUCTION}

Years from 2009, Chongqing strives to build the biggest NB production base in the Asia or even the global, and build the biggest intelligence cloud industrial cluster in the world, that will make electronic information industry be the pillar industry, and will promote economic structure adjustment and industry transformation upgrade, in this area.

From production to consumption, according to the upstream and downstream relationship, the whole NB industry chain can be divided into four major links: R\&D (Research and Design), PM (Production Manufacture), M\&S (Management and Service), Terminal. Each link has its key fields. The key fields of R\&D link includes PD (Product Design), SD (Software Design), Components; the key fields of PM link includes Parts of Chip and Core Manufacture (e.g. CPU(Central Process Unit), Chipset, Memory, PCB(Printed Circuit Board) and others), Integrated Manufacture; the key fields of M\&S link includes: Brand and Market Management, Services of transportation, warehousing, bonded, channel and bank; Terminal link is the directly users of NB[1].
The development of NB industry gave birth to a large number of high-quality personnel needs. Colleges and universities in Chongqing have important responsibility to cultivate qualified personnel for the NB industry chain. So we conducted a survey on the posts and personnel requirements of NB industry chain.

According to our survey, in NB industry chain, posts for graduates who have college degree or above to serve NB and other electronic information products mainly concentrated in production management, screen line engineers, connector engineer, software engineer, quality management, marketing, assembly and maintenance, financial, and so on. The main specialties included computer, electronic information, enterprise management, machinery, mechanotronics, marketing, e-commerce and logistics management and other related specialties.

Requirements of ability, quality and professional level for NB industry chain personnel are various in different posts. For general workers, specialty knowledge requirements are not strict, but must have good physical quality, pressure resistant ability, learning ability and practical operating ability.

Professional skills requirements of different posts are different. Some posts require personnel to master the popular software, main development platform and programming language (such as Java /C++/.Net /Android etc).

Some posts are strong professional. For example, the requirements for hardware engineer from a NB company are as follows. The applier must master NB circuit principle and design, use PCB Layout software, and have practical development experiences of NB PCB at least six-layer. Furthermore, he is familiar with standards such as EMI, 3C and so on. He has practical development experiences on processors of VIA C7 series, Intel Atom series and others. [2]

Our survey result is consistent with literature [3] on general skill requirements for personnel. On the whole, the NB industry chain need higher vocational and under levels graduates, who have more hardware aspect professional knowledge and technology, such as NB assembly and maintenance, electronic technology, SMT (surface mount technology) process, mechanical design and manufacture, production management, e-commerce, logistics, and others. 


\section{REFORMATION AND PRACTICE OF CURRICULUM SYSTEM}

To make good personnel training insurance for NB production base construction in Chongqing Xiyong Microelectronics Industry Park, Chongqing Municipal People’s government and education committee of Chongqing issued a series of preferential policy and personnel guarantee measures, so as to strengthen deep cooperation between schools and enterprises. More than fifty colleges and more than two hundreds secondary vocational schools were selected to serve as personnel training schools for NB production base, in order to fully play the function of education service for economic and social development.

In accordance with the government and education committee of this city, these schools gave a positive response and strengthened the cooperation with enterprises in NB production base. They revised personnel training mode and adjusted the curriculum set. Every year, around 100,000 intermediate and senior skilled personnel are trained, reserved and delivered for the NB production base.

In view of the personnel requirement situation of NB industry chain posts, higher vocational colleges should be targeted to reform the personnel training schema and curriculum system. Abiding by the principles of adaptability, characteristic development, entirety optimization, and higher vocational colleges should construct specialty dynamic adjustment mechanism, so as to add, eliminate and reform specialty to meet the personnel needs of NB industry chain. [4]

Curriculum is the key and foundation of high skilled personnel training in higher vocation education. The fundamental problem exists in many previous high vocation curriculums is the lack of students' vocational attainment. So we should construct curriculum system from the perspective of cultivating students' vocational attainment. [5]

Chongqing Information Technology College (CITC) was specified as one of the experiments colleges of NB production base personnel training. The college has done a lot of reformation practice about specialty curriculum system oriented NB industry chain.

The college had cooperated deeply with many global famous enterprises for a long time, which had entered in Chongqing NB production base, such as HP, Foxconn, Acer, Quanta, Inventec and so on. The cooperation mainly focused on the personnel needs forecast, personnel training and reserving, the curriculum setting and adjustment, curriculum system reforming, teacher cultivating and training, student practice and training, and so on. They had established longterm mechanism, realized win-win between the college and enterprise and developed together.

The college had opened some customized training classes for certain enterprises. Such as "president assistant class", "excellent software outsourcing Engineer class", "Zhongtian International class", "Foxconn class", "HP class", "Zhihe communication class", "new media technology class" etc.

The college adhered to the double certificate institution of "degree + skill", promoted the integration of teaching learning and doing. The college attaches great importance to the cultivation of students' vocational quality and revises its personnel training schema in accordance with the professional teaching standards of higher vocational colleges published by the Ministry of education; Drawing lessons from the "dual mode" of German, the TAFE (TAFE, Technical and Further Education) mode of Australian, the "Curriculum relying mode" of the United States, its curriculum systems were reformed;

Closely combining with the actual situation and work process, the college developed a curriculum standard which interconnected with the vocation posts standard and vocational attainment.

Every specialty curriculum system is divided into three models: the public elementary courses, vocational attainment courses and specialty intelligent courses. It embodies the rule of ability advancement from low to high. The public elementary courses include entrance education, ideology, morality and legal basis, college Chinese, college English (a), higher mathematics, computer basis, etc;

Vocational attainment course group include practical writing, speech and eloquence, art appreciation, traditional culture classics, vocational moral education, workplace mental health education, employment and career guidance, quality expanding, and so on.

Specialty intelligent course group can be divided into professional knowledge course group and professional skill course group. Professional knowledge course group include professional foundation courses and professional core courses, and professional skill courses include practices, training and graduation design.

Generally, all students have to practice, train, or take work experience in NB industry chain enterprises, such as HP, Foxconn, Acer, quanta, Inventtec, and so on, so as to cultivate their vocational attainments and professional practice skills.

The difference among specialties mainly concentrates in basic professional courses, core professional courses and professional direction courses. Other courses (such as public elementary courses, vocational attainment courses and professional skill courses) are basically the same.

While carrying out the concrete teaching, we not only use the traditional classroom teaching mode, but also use the micro class, online class and other teaching modes.

\section{REFORMATION AND PRACTICE OF TYPICAL SPECIALTY CURRICULUM}

The reformation and practice achievements of the college's curriculum system for the personnel needs of NB industry chain are introduced. The professional knowledge courses includes the eight specialties--electronic information engineering, applicable electronic technology, CAD and CAM, network technology, computer control technology, computer information management, software technology and ecommerce.

The electronic information engineering technology specialty has a closest relationship with the NB industry chain. The specialty is oriented electronic information industry to 
cultivate applied and high skilled personnel, who develops comprehensive on moral, intellectual, and physical, and meets the first-line requirements of electronic product design, production, sales and services. They have not only better electronic technology application ability, MCU(Micro Controller Unit) application ability and PCB design ability, but also one of the skills such as integrated circuit layout design, smart card application, SMT process management or audiovideo products service.

Based on the original electronic information engineering technology specialty, combined with NB production, targeted courses are opened. The main courses include "C programming", "circuit and electrical technology", "electronic circuit analysis and practice", "signal and network", " Electronic Design Automatic(EDA)", "MCU application technology", "electronic measurement principle", "signal processing technology", "PLC(Programmable Logic Controller) principle and application", "electronic device and electronic circuit", "smart card technology", "NB principle and application", "network basis", "DSP(Digital Signal Processing) small system debugging and fault analysis", "embedded small system debugging and fault analysis", "electronic process and SMT technology", "SMT equipment application and maintenance", "digital audio-visual technology", "sensor technology" and other characteristic courses.

In teaching practice, some concentrated practical training curriculums (electronic measurement technology, EDA, SMT electronic products production technology and NB assembly and maintenance, etc.), can be set to enhance students' skill of NB mainboard repair and skill of electronic products operation. The practice proved that students of this specialty can quickly start the work of PCB design and NB production and repair.

The applied electronic technology specialty has a closer relationship with the post skills of NB industry chain. The personnel needs of this specialty are great, so this specialty should be added in priority.

The major courses of this specialty include "circuit basis", "analog electronic technology", "digital electronic technology", "electrical technology and application", "C program design", "MCU application technology", "electronic production and inspection", "EDA technology and application", "sensor technology and application", "motor and electrical control technology", "electronic measurement technology", "PLC technology and application", "electronic product testing and debugging", "NB system maintenance and network technology", "PCB manufacture and debugging", "SMT equipment operation and maintenance", "audio and video equipment principle and maintenance", "modern communication technology", etc.

In teaching practice, some centralized practical training courses (electrician skill training, electronic product manufacturing technology practical training, NB computer maintenance practical training, etc.) are needed to strengthen the operation skills.

The main courses of computer network technology specialty include "computer network and application", "NB assembly and maintenance", "network hardware configuration and debugging", "integrated wiring and construction of network", "networking technology and network management", "network operating system", "server configuration and debugging", "network communication technology", "web design and making", "wireless network technology", "network database", "Java programming base", "dynamic web design(JSP, Java Server Page)", " technology and application of things network ", "network security technology and implementation", etc.

Some practical training courses ("computer network software practical training", "NB assembly practical training”, "NB networking practical training", and "website development integrated practical training", etc.) can be added. And corresponding courses or the curriculum contents for NB wireless networking can be added or adjusted.

The main courses of computer control technology specialty include "C program design", "electrical and electronics technology", "NB assembly and maintenance", "NB principle and interface technology", "VC++ development", "MCU principle and application", "converter technology", "automatic control principle", "computer control technology", "PLC technology and application", "computer network", "sensor technology", "NB product testing", "SMT equipment operation and maintenance", etc.

Around parts of these courses, some practice processes (such as metalworking practice, electrical and electronic practice, NB assembly and maintenance practice, course design of computer control technology, factory practice, etc.) should be increased. And students' repairing skills of NB interface fault and operating and maintenance skills of SMT equipment of production line should be mainly cultivated.

The main courses of CAD and CAM specialty include "mechanical drawing and CAD (computer aided design)", "mechanical engineering foundation", "electrical and electronics technology foundation", "tolerance coordination and measurement technology", "mechanical design foundation", "mechanical manufacturing foundation", "CAM (computer aided manufacture) software application", "NC (numerical control) machining technology", "hydraulic and pneumatic technology", "modern industry art of manufacturing", "industrial enterprise management", "UG mould design example", etc.

On this basis, some courses (such as "NB shell manufacturing and shaping technology", "NB product model design and manufacture", etc.) and their practical processes can be added for NB industry. In short, this specialty can set some courses for the NB product shaping and parts structure design and manufacture.

Based on the original website development management orientation and the ERP orientation, the computer information management specialty can appropriately add the application orientation of NB and related software, the orientation of information system maintenance, the orientation of ERP subsystems, or increase related skill courses for information collection and information processing.

The courses of this specialty include "OA(office automation) principle and application", "information management and 
operation", "accounting foundation", "graphic and image processing", "web design and making", "NB system and maintenance", "advanced language program design(C)", "computer network technology and management", "database management and maintenance(SQL Server)", "computer information security", "management information system", "accounting computerization", "ERP principle and application", "E-commerce and E-government", "CRM(customer relationship management) system, "NB supply chain management system", "SMT production technology and management", etc.

After the curriculum reforming of software technology specialty, its main courses include "web design technology", "graphics and image processing", "C program design", "NB computer assembly and maintenance", "computer network foundation", "SQL Server database technology and application", "ORACLE database", "data structure", "Linux operating system", "E-commerce", "multimedia technology", "JAVA program design", "C\# software project development", "JSP website development", "three frame of SSH(struts spring hibernate)", " ASP.NET web program design", "software engineering and project management", "NB testing technology", "development and application of embedded system", "Android platform application and development", etc.

Centralized project style trainings will be done around the main courses. This specialty can also be divided into a certain software orientation, such as JAVA, C\#, and embedded development etc. Furthermore, the curriculum should be adjusted according to the software application technology. Some courses (NB assembly and maintenance, NB testing technology, NB BIOS and drivers, etc) can be added for NB industry.

The courses of e-commerce specialty include "western economics", "enterprise management", "economic law", "market research and forecast", "E-commerce Foundation", "NB structure and product service", "network marketing", "computer network technology", "C\# program design", "Ecommerce database", "E-commerce website planning and construction", "management information system", "supply chain and logistics management" etc.

This specialty can adjust appropriately curriculum system to concentrate on the supply chain and logistics management of NB industry chain enterprise or the sales and product service skills of NB related products.

\section{CONCLUSIONS}

Curriculum is the key and foundation of personnel training and an important way for students to acquire the knowledge and skills. While the industry transforming and upgrading, the personnel training scheme should be revised and curriculum system should be adjusted timely according to the posts requirement, so as to adapt the market need change for personnel.

According to the personnel standard of NB industry chain, higher vocation colleges can add some specialties, which have greater personnel requirements, such as electronics specialty and electromechanical specialty. They can reduce irrelevant theory courses in the original specialty, embed some characteristic courses, and add some courses of SMT technology closely related to NB production. Furthermore, they can change the name of part courses. For example, the course name "computer assembly and maintenance" is changed to "the NB assembly and maintenance". This can reduce the theoretical knowledge and enhance the pertinence. It can not only cultivate the vocational attainment of NB industry chain, but also alleviate the employment pressure of current college students; at the same time, the students may learn more easily, and teachers may teaches more relaxed.

Practice has proved that the curriculum reformation around the NB industry chain in Chongqing Information Technology College is effective.

\section{ACKNOWLEDGMENT}

The work described here was partially supported by the Key Project of Teaching Reforming Research for Higher Education in Chongqing (Grant No. 102416), and the Key Project of Eleventh Five-Year Plan for Chongqing Educational Science (Grant No. 2010-GJ-5202).

\section{REFERENCES}

[1] Yaoping Wang. “Optimization and improvement of industry chain investment patterns (tack Chongqing Xiyong Micro-Electronics Industry Park as an example)". Chengdu, Southwestern University of Finance and Economics Master Degree Thesis, 2010.

[2] Zhongbo Deng, Xinyuan Liang, Kaifeng Kang. "Personnel needs and training strategies of notebook computer industry chain”. Chinese management informatization,2014,issue 6, pp.102-105.

[3] Jiangdong Lu, Yongjun Lou. "Enterprises survey on the general ability of higher vocational graduates". Vocational \& Technical Education Forum,2012, issue 14, pp. 89-91.

[4] Jianhua Wang, Jianping Zhang. "On the analysis of dynamic adjustment mechanism of specialty in higher vocational colleges”.China Higher Education Research,2014, issue 12, pp. 75-78.

[5] Chiwen Wei, Higher vocational curriculum reflection and construction based on vocation attainment education[J].2014,(11):138-140.

[6] Cuihong Zuo, Haibo Chen, Ruihua Zhu. SMT equipment operation and maintenance. Beijing, Higher Education Press, January, 2013.

[7] The ministry of education, Vocation education and adult education department, Professional teaching standards of higher vocation school (Trial): electronic information categories. Beijing, Open University of China Press. November., 2012.

[8] Zhengling Tang, Guoqing $\mathrm{Xu}$, “A comparative study on standard development mode of vocational education professional teaching of Anglo American”. Vocational \& Technical Education Forum, 2014, issue 13 , pp. 14-18. 